\title{
"Sister Akua, they say you should dance": negotiating roles in participant observation
}

By Elizabeth Graveling (University of Bath)

Relationships, and specifically the relationship between the fieldworker and the research subjects, are at the core of the process of all anthropological and ethnographic research and to a very large extent determine the outcomes of the research. In addressing the question of how far a participant observer should attempt to "become" a member of the group she is studying, we must also recognise the complexity of individual and social identities assumed or attributed to her. When the distinction between aspects of "self" and "other" is blurred, the fieldworker can be simultaneously (but not fully) "insider" and "outsider" in different facets of her identity and in different relationships. Drawing on experiences of recent ethnographic fieldwork among members of churches in a village in southern Ghana, this paper explores aspects of identity that contribute to this ambivalent status of the fieldworker. It considers the extent to which the researcher has control over her research roles and the implications of this in terms of access, acceptance, data collection, and obligations and responsibilities of the researcher to her informants.

In all qualitative studies it is essential to consider the nature of the relationship between the researcher and the research subjects and the extent to which this influences the research. Participant observation by definition requires reflection on its two elements, participation and observation. The classic typology of potential roles for fieldworkers involved in this kind of research ranges from "complete participant", through "participant as observer" and "observer as participant" to "complete observer" (Gold 1969). Gans (1968) uses the terminology of "total participant", "researcher-participant" and "total researcher", while Adler and Adler (1987) place the emphasis on membership: "peripheral-member", "active-member" and "completemember" researchers. Whichever typology is employed, the main considerations are the extent of the fieldworker's participation in the activities of the group $s /$ he is studying, and the extent to which members of that group are aware of being studied. Here I focus on the first of these questions. However, instead of asking which role is appropriate for a researcher to adopt, I highlight the ambiguity, multiplicity and fluidity of these positions and address the question of how the role of the fieldworker and the relationship between her and her research subjects are constructed by both parties. Using extracts from my fieldnotes on ethnographic research within two churches in a Ghanaian village, I examine the active construction of my position firstly by the people around me and secondly by myself, before discussing the aspects of identity which inform these constructions in terms of social difference. While I consider social identities such as race, age and gender, in this research religious identity is crucial and forms the focus of the paper. 


\section{Context of the research}

The fieldwork on which this paper is based was carried out between March 2005 and October 2006 in a village in southern Ghana, as part of a research project situated within the field of development studies which seeks to balance development theoreticians" focus on "faith-based organisations" and "faith communities" as homogenous bodies with an account of the complexity of lived reality. The objective of the fieldwork was to explore how religion is played out in the everyday lives of church members. It was carried out through ethnographic techniques, mainly participant observation and semi-structured interviews.

The location of the research is a village of approximately 2,000 residents on the coast of Ghana, where the economy is based mainly on cash-crops, fishing and tourism. Although tourism provides some employment and greater exposure to the outside world than is the case in more remote villages, few of the higher positions requiring secondary or tertiary education are occupied by local people and most residents struggle to make ends meet. The village consists of a mixture of mud and thatch buildings alongside concrete structures with corrugated iron roofs. Water is drawn manually from a few public and private wells and many houses are connected to an unreliable electricity supply. As a (white) foreigner I was therefore immediately perceived as extremely wealthy which, in relative terms, I was.

My accommodation in the village was within a household consisting of the landlady and a constantly changing mixture of her extended family. My landlady was also the pastor of one of the churches I was studying, the indigenous Musama Disco Christo Church (MDCC), founded in the 1920s and mirroring the social structures of Fante society, with a strong emphasis on spiritual activities, prophecy, dreams, visions and healing through ritual and liturgy. The congregation, usually numbering around 50, meets in a building constructed of bamboo on the outskirts of the village and consists almost entirely of women, most of whom have little or no education. The second church was the Pentecostal Assemblies of God (AG), which originated in the USA although it is now autonomous within Ghana. The AG identifies strongly with the Global Pentecostal movement: rejecting ritual, it is strongly Bible-based and associates itself with modernity. A typical Sunday service is attended by between 12 and 20 members (of whom about six are likely to be men), of varying levels of schooling from none to university, who meet in a concrete structure yet to be completed near the centre of the village. Both churches use the local languages of Fante and Ahanta, although many people also speak English to varying levels.

\section{Fieldwork on "their" terms}

Working with people, particularly in a foreign environment, means foregoing a certain amount of independence. I was continually dependent on others for my basic living, my understanding of life and the practical carrying out of my research. My role as participant-observer was thus partly determined by how the people I was studying involved me in their activities and positioned me within their world. Members of both churches took an active role in including me and determining my participation in the church context. As I considered my role in their lives, they were also concerned with their participation in my life, whether as hosts, as "brothers and sisters in Christ", as church leaders or as potential beneficiaries of my relative wealth. 
Particularly at the beginning of the fieldwork, working in a foreign language and with limited local and cultural knowledge, I was very much in the hands of the church members during meetings, dependent on them for my understanding of what was happening. In that sense the balance of power came down heavily on their side. I had no choice but to be dependent on them, and I soon realised that the extent of my participation in the churches would not be purely on my own terms. During AG meetings I was continually encouraged to join in. I was expected to contribute to discussions, encouraged to dance with the women, and often asked to read a Bible passage or to pray. This active inclusion extended beyond the church building: I was also expected to join the congregation in, for instance, visiting a bereaved family, evangelising in the community and attending regional events.

Within MDCC church meetings, too, I was not entirely free to decide how I participated. During the last service I attended I made a donation towards the church building:

Fieldnotes 15/10/06: Having made a short speech in Ahanta thanking them for their help and hospitality during my stay, I handed over the money and sat down again. But on the pastor's direction one of the women put a chair in the centre of the room and they asked me to sit there. The elders and choristers gathered around me and started praying for me. When they had finished I got up to resume my usual seat, but the pastor, after some discussion with other members of the church, came over to me and explained that they wanted me to sing to the church [as people often do when they make a special offering]. So I pushed down inhibitions, told myself it would be much easier to comply than to refuse, and sang. Again I tried to sit down, and again the pastor came up to me. "Sister Akua, they say you should dance. You have to lead them."

In this case I still had the option of declining: having laid out their expectations, it was left to me to decide whether or not to concur. After spending more than a year attending this church, getting to know its members and participating in (although never leading) its dancing, it was far less difficult to accept (and far more difficult to refuse) this request than it would have been at the beginning of my fieldwork. The process of fieldwork is bound up with trust, on the part of the researcher as well as the respondents. It was only as I grew to trust these people and to build up a relationship with them that I felt less awkward and more relaxed, and was able to participate more fully in their activities and lives. Conversely, it was through participation, which involved both overcoming fear, pride and self-consciousness, and yielding to their wishes regarding the nature of my participation, that our mutual trust increased.

Sometimes, as in this instance, my inclusion in the meetings lessened the distance between myself and church members. At other times it had the opposite effect. This was especially clear in my assigned and non-negotiable seat at every service, next to the pastor at the front of the church, facing the congregation, or the impromptu roles I was sometimes given, for example during the offering when people were instructed by the pastor to shake my hand after placing their donation in the basket.

The AG pastor in particular considered me to a certain extent as a new member of his church, to whom he had obligations and responsibilities such as including me in his rounds of visiting church members at their homes. However, I was never seen as a full member of either church, for several reasons. Firstly, I was known to be a member of an Anglican church in the UK (when at the end of my fieldwork I donated some chairs to the AG, in his acceptance speech the pastor commented, "She is not even an Assemblies of God member, she is an Anglican"). Secondly, I did not attend every 
meeting because, as the congregations knew, I was also visiting other churches. This in itself was not an issue because - and thirdly - my purpose as a researcher was made clear from the beginning, so I was not expected to be fully committed to either church.

Similarly, in non-church contexts my role was partly decided for me. At a traditional baby-naming ceremony for a woman within my household I was pleased to be directed to participate as one of her sisters, while at other times my role was constructed in ways I did not desire. Occasionally, for example, when somebody came to the house to request financial help and I was not in, my landlady would make the decision for me, giving money on my behalf for me to reimburse her later. Others in the household continually highlighted my status as a stranger by insisting on demonstrating hospitality towards me, for instance taking dishes from me as I washed them.

Research subjects could also influence my role as participant-observer by choosing the degree to which they would participate in my research. Some would repeatedly ask to be interviewed, others refused when I asked them.

Fieldnotes 18/07/06: Earlier I approached some of the women in the house to ask them what makes people "good" and "bad" in Ghanaian society. They fell silent and didn't say anything. Nothing at all. They said some things to each other in Fante, but nothing to me. Emma [from a different West African country] muttered something about it being Ghana so not about her and went downstairs, Adjoa said she didn't understand, then after a while said something about "rasta boys", but when I asked for more she said "some are good, some are bad" and wouldn't elaborate. Beth wouldn't even look at me. [...] It's like they just go wooden whenever I ask anything - close up completely.

People have different reasons for not wanting to participate in research. In this case it appeared to be a reluctance to state opinions "on the record" and in the hearing of others. Another time a woman said she felt she would not understand or know what to say. A further rationale for non-participation appeared to be an unwillingness to reveal or discuss aspects of one's life which could be seen as shameful. Whatever the reason, by refusing to accept the way I attempted to conduct my fieldwork, people forced me to reassess both our relationship and my methods of gathering data, for instance using informal conversation while we were alone rather than structured questions in the hearing of others, sometimes focussing on opinions and third-party rather than personal stories, and taking extra care not to appear judgmental.

The fieldworker's role is therefore determined largely by the people she is researching. Sometimes they insist on a greater level of participation and identification than she might wish; sometimes they choose to highlight the differences between themselves and the researcher more than she may desire. They can also reject the terms of the relationship offered by the fieldworker by refusing to cooperate with her wishes. I discuss below how the research subjects position the researcher according to their understanding of how a stranger, a member of a different church, a researcher, a sister, a European, a person with wealth and education should be treated. This is informed and shaped by the social structures in which they live, thus the fieldworker is not restricted simply by the actions and decisions of individuals, but by overarching structures within which she also must operate to negotiate her position (Irwin 2006). 


\section{Fieldwork on my terms}

I was also active in determining my own role as a participant-observer. I continually made decisions about my actions within church meetings, a reoccurring example of which concerned offerings. Financial contributions form an important element of membership of many groups in Ghana, including the family, where better-off members are expected to contribute to the needs of poorer relatives and communal family expenses such as funerals. A similar principle operates in churches, which usually receive little or no funding other than contributions from members. Both churches in this study are in the process of constructing new buildings, and both pastors are fully financed by their congregations. These expenses, plus obligatory financial contributions to the respective district or regional church office, result in churches requiring substantial support from their members. This is normally collected in the form of church offerings, of which several may be taken during a service, often in a very public manner which makes it clear to the rest of the congregation what each person has given. My ambiguous status as a temporary, semi-member of two churches, along with my obvious relative wealth in comparison with others in the congregation, left me constantly unsure of how much to give. I was also aware of how my motivations for giving might differ from those of people around me, and how my own moral values (for example, regarding anonymity in giving or financial demands on poor people) influenced my view of the offerings. The consequences of participation or non-participation in this area were therefore multiple and my decisions were the product of several considerations, related to moral values (I don't want to reinforce practices I don't agree with); research, social and personal needs (I don't want to accentuate differences between us; I don't want to offend them; I want them to think well of me); research ethics (I don't want to influence or change my research subject); altruism (I want to help them); and personal religious values (I want to give to God). Each time I took part or declined to take part in an offering my action had consequences in all of these areas, whether or not I considered them at the time.

Particularly within the MDCC, I had to consider how far I wanted to participate in activities that did not entirely concur with my own religious values.

Fieldnotes 24/08/06: I'm not comfortable with many of the MDCC rituals and doctrines - calling angels, multiple offerings, communal bathing with prayedover water, candles, incense, oil. Polygamy, animal sacrifice [...]. On the one hand I don't want to judge it - it's not my role and I don't have the right to say whether what people here are doing is right or wrong. On the other hand, it's so far removed from what I've been taught and brought up with that I can't just accept it and take part in it. [...] I can see that this might suit particular people here, fit in with Ghanaian culture, but I'm not those people, I'm not Ghanaian. So how far do I "participate" in my observation? Where's the line between trying to understand and compromising my own values?

At an MDCC festival I passed a stall selling the Musama copper crosses and rings worn by MDCC members, and the pastor I was with asked if I wanted to buy some. I said I would like to as a souvenir, but was not sure if it would be correct behaviour since I was not a member. She responded that it was fine, and then encouraged me to wear them, also telling others that I had bought the items. Now I had a dilemma. The people I was with were obviously very pleased that I had bought the jewellery, and did not understand why I should buy it if I did not intend to wear it. The items were a sign of identification with the church. To refuse to wear them would have been to refuse to be associated with the MDCC and thus may have caused offence, whereas to 
put them on may have given a false impression of my relationship with the church, both to its members and to non-members who are not necessarily sympathetic to the MDCC, as well as associating myself with activities and doctrines I did not necessarily agree with. I had a similar experience with the T-shirt and cap I was instructed to purchase in order to participate in the AG $75^{\text {th }}$ anniversary celebration, although these were only expected to be worn on this one-off occasion.

How I represented myself to others, therefore, often had ethical implications, particularly regarding transparency and sincerity. There is a difference between attempting to understand a group of people and actually becoming one of them, and although the researcher may know where she stands (which is not necessarily the case), it may not be obvious - or may appear differently - to members of the group. Although I tried hard to be transparent in my research, this was not always possible in situations such as that described above where most of the thousand or so people at the MDCC festival had no idea of my identity and were delighted to see a European apparently joining their church. Moreover, the researcher's assumptions regarding others' perceptions of her are not always correct. I later discovered that Musama jewellery, although engraved with the initials of the church, is not worn exclusively by church members. Non-members, even members of other churches, sometimes wear it, or more often put it on their children, considering it to provide spiritual protection. It is likely that my desire for ethical "correctness" was not such an issue for the MDCC members, who appeared very happy to see me don their jewellery on a temporary basis without worrying about any implications of this beyond the immediate act of "joining in". In this sense, as Blanes (2006) notes, the issue of "belief" may be relocated from the ethical to the methodological, as a matter of ethnographic politics.

There is, however, another side to the question of transparency and honesty. I felt uncomfortable wearing Musama jewellery because it symbolised something I did not necessarily believe in. On the other hand, I was much more at ease identifying with and wearing the symbols of the AG church, partly because I was aware that as a church the AG was generally more accepted and respected in Ghanaian society than the MDCC, but also because the teachings and practices of the AG correspond more closely (although not entirely) with my own values. The question here is to what extent we should compromise our own principles in order to understand others better. Angrosino and Mays de Pérez (2003:127) discuss issues of deception and the pressure (and guilt) often felt by female researchers "to conform to the gender behavior norms of the cultures they study, even if those norms are not the ones they would freely choose for themselves", contrasted against possible negative consequences of "defy[ing] the norms of the community being studied". This issue is particularly pertinent in research on religion, when the researcher holds religious convictions that she considers morally wrong to transgress, and especially when her religious identity is strongly rooted in a community external to the field, her home church. Unable to reconcile some of the practices in these churches with my own beliefs and moral values, I was faced with the dilemma of not participating and thus distancing myself from the church members, or taking part and thus actively involving myself in things which contravened not only my own beliefs, but my beliefs as part of a community I valued and to which I would return at the end of my fieldwork. Dancing with the congregation at a normal Sunday service did not pose any moral dilemmas, but the same direct request at an evening prayer meeting where dancers often enter trancelike states would have caused me problems. Contrary to Wacquant's "call to moral 
and sensual immersion in the field" (Wacquant 2004 in Irwin 2006:157), I usually remained a non-participant observer in such situations. I changed my behaviour where it did not compromise my moral or religious values: for example, I conformed to expectations in clothing at church, having Ghanaian-style outfits made up and wearing a headscarf at the MDCC festival. Outside church too, I endeavoured to conform to local behavioural standards and conventions, for instance wearing appropriate clothing, abstaining from alcohol and eating in the local manner. This was important not only in order to demonstrate respect for my host community, but also for people to trust me and take me seriously. That such efforts were noted by the community was clear from the running commentary I received, including criticism (a respondent at a funeral: "no, you are wearing pink, it is not good"); instruction ("go and change to black"); and praise ("good, now you are Ghanaian").

As I gained more knowledge of the cultural context, I was able to understand better how different facets of identity were constructed. I could therefore not only start to understand how other people constructed my position; I could actively engage with this to influence my role as participant/observer. The particular aspect of my identity that I emphasised in any situation made a great difference to my data, as is clear from the example mentioned above of women refusing to answer my questions, compared with a second situation involving one of the same women where I took a different approach:

Fieldnotes 28/07/06: I sat in the courtyard and chatted to Emma, who's smoking some fish down there. She's very willing to talk when it's not formal - and perhaps when others are not around.

In the second situation I remained within the role of "sister", whereas in the first I stepped out of that role. In this context, if I presented myself as a researcher I would get little response beyond an awkward silence, a refusal to meet my eyes and a change of subject. If, however, I downplayed that aspect of my identity and, in this case, emphasised my similarity with Emma in age, gender and non-Ghanaian status, in the context of a general conversation I could ask anything and receive friendly, natural responses. As Mama (1995:99) asserts in her study of subjectivity among black women in Britain, "[i]ndividuals have many discourses and discursive positions available to them, and the positions they take up are momentary, changing with the different social contexts and relations they find themselves in". As most people do consciously or unconsciously in everyday life, I stressed different facets of my identity in different contexts, for example, my religious orientation at church and my professional status when visiting offices. With older women I would follow the cultural conventions of respect; with younger men I might highlight my superiority in age so as to gain respect from them. I would also sometimes deliberately emphasise my outsider status as a European, so as to appear ignorant and wanting to learn rather than inquisitive and demanding.

The relationship between researcher and research subjects is therefore mutually constructed and negotiated, informed by the socio-cultural background of each. Insofar as she has the freedom to do so, the fieldworker continually makes decisions regarding her level of participation. These decisions may have several different bases (moral, religious and professional values; personal, social and research needs) which will not necessarily concur with the worldview of her research subjects. As she becomes better acquainted with the context of her study, she gains in potential to vary the extent of her participation and manipulate relationships in order to achieve her own aims. 


\section{Social difference}

Discussing "Self" and "Other", Michelle Fine talks about "working the hyphen" ("Self-Other"), recognising that these are not two distinct categories: "By working the hyphen I mean to suggest that researchers probe how we are in relation with the contexts we study and with our informants, understanding that we are all multiple in those relations" (Fine 1994:72, orig. emph.). During my fieldwork I simultaneously played various roles in relation to the people around me, and these changed over time. For instance, to my landlady, who was also a pastor, I was both tenant and church attendee. As a younger woman I was also considered her daughter (acquaintances would ask after my "mother"); I was a sister to other women in the household and an aunt to their children. To some of my research assistants I was an employer and a friend; to one I was a granddaughter. To almost everybody I was an actual or potential source of financial support. And I was also, of course, a researcher.

These roles involve different rights and responsibilities, specific to the local culture. However, identities are constructed through perceptions of difference (Hall and du Gay 1996, Hunt 2002), and roles are negotiated in every relationship. As an oburoni (white person) I was always different and constructed my own unique position in relationship with the people around me, continually renegotiated in each situation and in relation to each person I came into contact with. As Haraway puts it, my identity was "a kind of disassembled and reassembled unity" (Haraway 1991:74). My relationship with my "mother" was different from her relationship with her other "daughters" in the household (also not daughters by birth): the power dynamic flowed in two directions, based mainly on her seniority in age and my white skin, education and greater wealth. For example, she expected me to address her with respect, but not to serve her like the other women. Sometimes she would request financial help from me, whereas my "sisters" were mostly supported by her. So our relationship was mutually constructed, through the way she positioned me in her world and viewed her own rights and responsibilities regarding me, and the way I positioned her within my world.

My position at any given moment was determined by the complex interplay of different axes of social difference, such as race, gender, marital status, education, age, wealth and religious orientation, and continually renegotiated by myself and others in different contexts. This inevitably affected the data I was exposed to as well as how I interpreted them: as Angrosino and Mays de Pérez (2003:133) point out, "different ethnographers - equally well trained and well versed in theory and method but of different gender, race, or age - might well stimulate a very different set of interactions".

Seeing as an outsider and being seen as an outsider had both advantages and disadvantages. People had no reason to trust me, a stranger coming to inquire into their affairs and then leaving again. Yet sometimes it is easier to talk openly to someone who is not close to you or your friends and family than to someone who is. Furthermore, an outsider coming into the community has no established ties or loyalties, although these are inevitably formed as she settles into the community. As an outsider I faced the danger of failing to understand my respondents' perspective. I would never be "one of them"; it is never possible fully to see through someone else's eyes. I did not have the basic background knowledge and understanding that comes from being brought up in the society and which is usually taken for granted. But not 
taking things for granted is the essential advantage of the outsider: everything is questioned, everything analysed from a perspective difficult for an insider to attain.

Noaks and Wincup criticise the notion that ethnography is about telling a story from the participants' own perspective:

"Telling it like it is" implies presenting an account of the social world from the perspective of those being researched; telling the story as they would tell it (based on the unlikely assumption that they would all tell the same story). This is an overly simplistic view because if an ethnographer were to do this, he or she would have "gone native", in other words become so immersed in the culture they were studying that they had left their academic culture behind. (Noaks and Wincup 2004:92, orig. emph.)

Literally to "tell the story as they would tell it" would involve forsaking analytical and theoretical tools, since the research subjects are not likely to use these in their narratives. However, it is essential through applying these tools to get as close as possible to understanding the experience of those being studied, and respondents do have "voice" in the research narrative. Thus, the story told is the perspective of the research subjects from the perspective of the researcher - my story of their story.

The most obvious defining aspect of my identity while in Ghana was my race. During my first experience of Africa, in Togo, I wanted desperately to conceal my white skin because, unlike in the UK, there it is not politically incorrect to call attention to such differences. Every day I was reminded of that difference by how I was treated, spoken to and expected to act - and by people calling out "white lady" (yovo in Togo, oburoni in Ghana) as I passed. In Togo I realised that this is not demonstrative of racial tension, but rather the lack of it: it is not necessary to hide differences. In Ghana I began to understand that the issue is more complex. Tensions are embedded within this literally skin-deep difference: skin colour is symbolic. White skin symbolises privilege, which can be simultaneously aspired to, resented and disdained by people who have little money or employment prospects, are denied visas, struggle for education, feel oppressed by corrupt officials, yet may be physically very strong, possess knowledge and skills that most white people do not, and have deep-seated moral and cultural values. It symbolises wealth, opportunity, freedom to travel, education, power, and sometimes oppression and moral laxity. It conveys messages about what you eat and how ("Do you know how to eat fufu?"), which products you buy ("The whites like this toilet paper because it is soft"), and what kind of work you can or will do ("Who washes your clothes for you?"). Some of these assumptions can be challenged while others cannot. Moreover, attributes symbolised by white skin are not conditional upon it. Many Ghanaians are also powerful, educated and wealthy with good jobs and the ability to travel, and this difference is also felt.

It is not, then, simply the colour of my skin that determines how I am viewed and treated. I may be spoken to in a certain way because I am educated, not because I am white, but perhaps my white skin acts as an indication of my education. My seat at the front of the MDCC was not simply down to the colour of my skin, but the fact that I am white acted as an indication of other social differences that, in the members' view, required me to be placed there, for example that I was a relatively rich and educated stranger.

As we have seen, a second aspect of my identity that proved very significant, particularly given the area of my research, was my religious beliefs. In Ghana most people's cosmologies include different kinds of spirits, with Christianity particularly 
influential in the south. Many of the local population are mystified as to how anyone can deny the existence of God, although they are aware that this is the case for many white people. As a Christian I was accepted into the churches and encouraged to take an active role in them, while shared beliefs also contributed to how I was positioned in social relationships outside church. Regardless of belief, however, attending church demonstrated a willingness and a desire to participate in people's activities, learn from and with them and associate myself with them.

Some aspects of my identity implied vulnerability within Ahanta society. In a maledominated culture where age is respected and the value of producing offspring is high, I was working as a single woman in my late twenties: both young and without children. Sometimes these vulnerabilities caused me problems: unwanted attention from men, the necessity to show deference to older people. But often I found advantage in vulnerability, which led other people to position me as non-threatening and in need of assistance and information. When one needs people's trust it is important not to be seen as a threat. Often being ignorant or incapable - and willing to ask for help - goes a long way in forming relationships.

My "strengths" (such as wealth and education), although facilitating access to people with high social status, often turned out as hindrances and barriers to close friendships, underlining differences and imposing distance. On the other hand, relationships are mutual and I could use my strengths to benefit the people around me (for example through small gifts of money, payment of medical expenses, helping children with their studies, taking photographs of people), just as they used their knowledge and skills to help me. There is a difference between interacting with people and trying to influence the way they live - and differences in opinions as to the appropriate ethical stance on this (Atkinson and Hammersley 1994:253, D'Andrade 1995, Scheper-Hughes 1995). The tradition of objectivity that claims that researchers should not get involved with their research subjects and should endeavour to carry out their work without causing any change at all to the environment in which they are working has been critiqued by the interpretive, feminist and postmodern paradigms (Irwin 2006:157). Without endorsing the deliberate "[c]omplete bodily and emotional immersion" that Irwin (2006:157) identifies in some of the interpretive literature, it seems that remaining completely detached would not only be a hindrance to research, but also impossible, because simply entering a community inevitably affects people's lives in some way, if not materially then socially and psychologically.

Referring to research roles, de Laine states:

The researcher takes to the field a bundle of roles that constitute the total social "me". Which role will be allowed to assume a master and determining status in any social setting, and which roles are to be relegated subsidiary positions in the repertoire of roles, might be a matter to be negotiated with another/others. (De Laine 2000:116)

However, the negotiation may not be over which role the researcher is allowed to play in any given context so much as the construction of the role itself, which must be performed collaboratively by both researcher and research subjects. Whatever the researcher may take to the field, once she is there her identity is modified in relation to her social environment. Rather than being reorganised within a fixed repertoire, roles become fluid and ambiguous as the constituent elements of identity through which they are constructed are renegotiated. 


\section{Conclusion}

Discussions of research roles in participant observation generally focus on the question of which role is appropriate for the fieldworker to adopt in a given context for a given purpose. These roles are sometimes portrayed as costumes ready to be put on according to the researcher's wishes. Here I am shifting the focus to how the role of the participant-observer is determined, rather than on why the fieldworker should adopt a particular role. Far from ready-made costumes, research roles are mutually constructed by the researcher and the research subjects, based on the complex interplay of various aspects of the former's identity in relation to the latter and constantly renegotiated within a framework of social difference. In placing the focus on how the role of the participant-observer is determined and acknowledging the active contribution of the research subjects to that process, we get away from the simple question of which role is suitable for a fieldworker to adopt, and recognise the restrictions on the ability of the fieldworker to carry out research on her own terms, with regard to both the active construction of her role on the part of others and the social structures within which the terms of relationships are negotiated.

The emphasis on continual negotiation and renegotiation is important, firstly because relationships (outside as well as within the research arena) are not static but continually changing and developing and, secondly, because the same relationships are co-constructed by both (or all) parties. Developing relationships may affect interests and will certainly affect levels of trust on both sides. In a religious context, intrinsic to this process are often issues of belief and values where, given both the expectations and constraints placed on her by her respondents and her own compulsion to remain faithful to her religious values, the researcher must continually make decisions regarding the level and nature of her participation. An intimation like "sister Akua, they say you should dance" and its acceptance, then, may represent not only a slightly amusing incident of a researcher being placed in an uncomfortable position by the subjects of her research, but also the outcome of a mutually trusting relationship that has developed over several months; a step in the process of further developing this relationship; a personal ethical stance on the part of the researcher; and a continued negotiation of identity as part of the politics of research that has serious implications for the nature of the data.

\section{References}

Adler, P.A. and P. Adler. 1987. Membership roles in field research. Newbury Park, CA: Sage.

Angrosino, M.V. and K.A. Mays de Pérez. 2003. Rethinking observation: From method to context. In Collecting and interpreting qualitative materials, eds. N.K. Denzin and Y.S. Lincoln, 107-154. London: Sage.

Atkinson, P. and M. Hammersley. 1994. Ethnography and participant observation. In Handbook of qualitative research, eds. N.K. Denzin and Y.S. Lincoln, 248-261. London: Sage.

Blanes, R.L. 2006. The atheist anthropologist: Believers and non-believers in anthropological fieldwork. Social Anthropology 14(2), 223-234.

D’Andrade, R. 1995. Moral models in anthropology. Current Anthropology 36(3), $399-408$. 
De Laine, M. 2000. Fieldwork, participation and practice: Ethics and dilemmas in qualitative research. London: Sage.

Fine, M. 1994. Working the hyphens: Reinventing self and other in qualitative research. In Handbook of qualitative research, eds. N.K. Denzin and Y.S. Lincoln, 70-82. London: Sage.

Gans, H.J. 1968. The participant-observer as human being: Observations on the personal aspects of field work. In Institutions and the person: Papers presented to Everett C. Hughes, eds. H. Becker, B. Geer, D. Riesman and R. Weiss, 300317. Chicago: Aldine.

Gold, R.L. 1969. Roles in sociological field observations. In Issues in participant observation: A text and reader, eds. G. J. McCall and J. L. Simmons, 30-39. Reading, Mass.: Addison-Wesley.

Hall, S. and P. du Gay, eds. 1996. Questions of cultural identity. London: Sage.

Haraway D. 1991. Simians, cyborgs and women: The reinvention of nature. New York: Routledge.

Hunt, S. 2002. "Neither here nor there": The construction of identities and boundary maintenance of West African Pentecostals. Sociology 36, 147-170.

Irwin, K. 2006. Into the dark heart of ethnography: The lived ethics and inequality of intimate field relationships. Qualitative Sociology 29, 155-175.

Mama, A. 1995. Beyond the masks: Race, gender and subjectivity. London: Routledge.

Noaks, L. and E. Wincup. 2004. Criminological research: Understanding qualitative methods. London: Sage.

Scheper-Hughes, N. 1995. The primacy of the ethical: Propositions for a militant anthropology. Current Anthropology 36(3), 409-440.

Wacquant, L. 2004. Body and soul: Notebooks of an apprentice boxer. Oxford and New York: Oxford University Press.

\section{Acknowledgments}

This paper is based on doctoral research carried out in 2005-06 and funded by the ESRC. Thanks to Dr Joe Devine and Dr Sarah White of the University of Bath for their thoughts on the original paper, presented at the Researching Africa Day Workshop, St. Antony's College, Oxford, 24th February 2007.

\section{About the author}

Elizabeth Graveling completed her PhD at the University of Bath in 2008. Her thesis is entitled "Negotiating the Powers: Everyday Religion in Ghanaian Society". She currently lectures in the field of Development Studies within the Department of Economics and International Development at the University of Bath and can be contacted at E.Graveling@bath.ac.uk 